\title{
Pressupostos metodológicos para análise do fenômeno religioso: a contribuição de Angela Ales Bello em diálogo com Husserl e Edith Stein*
}

\author{
Methodological Assumptions for Analysis of the Religious Phenomena: \\ the Contribution of Angela Ales Bello in Dialogue with Husserl and Edith Stein
}

\section{Clélia Peretti**}

\section{RESUMO}

O presente artigo discute os pressupostos metodológicos para o estudo do fenômeno religioso a partir das linhas traçadas por Angela Ales Bello, filósofa italiana, intérprete do pensamento de Edmund Husserl e de Edith Stein, em suas várias obras. A tarefa desta pesquisa consiste em compreender como a filosofia fenomenológica pode contribuir para repensar as estruturas internas do sagrado e especificar o papel da Fenomenologia da Religião no aprofundamento da experiência religiosa. Ales Bello, seguindo os passos da fenomenologia husserliana e steiniana, propõe, como ponto inicial para o estudo das religiões, uma análise antropológica. As indicações advindas do método fenomenológico de Husserl e de Edith Stein revelam-se como instrumentos úteis para entrar nos meandros das dimensões sacro-religiosas e para compreender o sentido profundo da experiência religiosa e mística. O conteúdo do artigo deixa transparecer o encontro de Angela Ales Bello com a fenomenologia de Husserl e de Edith Stein, seu "encantamento" pela busca humana da verdade e pelo seu filosofar estritamente entrelaçado com a vida.

Palavras-ChaVe: Fenomenologia. Fenomenologia da Religião. Angela Ales Bello. Husserl. Edith Stein.

\section{ABSTRACT}

The present article discusses the methodological assumptions for the study of the religious phenomenon according to the lines drawn in the various works of Angela Ales Bello, Italian philosopher, interpreter of the thinking of Edmund Husserl and Edith Stein in his various works. The task of this research is to understand how phenomenological philosophy can contribute to rethinking the internal structures of the sacred and to specify the role of the Phenomenology of Religion in the deepening of the Religious experience. Ales Bello, following the steps of Husserlian and Steinian phenomenology, proposes, as an initial point for the study of religions, an anthropological analysis. The indications derived from the phenomenological method of Husserl and Edith Stein prove to be useful tools for entering into the intricacies of the sacro-religious dimensions and for understanding the profound meaning of religious and mystical experience. The content of the article reveals the meeting of Angela Ales Bello with the phenomenology of Husserl and Edith Stein, her "enchantment" for the human search for truth and for her philosophies strictly intertwined with life.

KEYWORDS: Phenomenology. Phenomenology of Religion. Angela Ales Bello. Edmund Husserl. Edith Stein.

\footnotetext{
*Este artigo é fruto de pesquisas realizadas no Pós-doutorado em 2015 no Centro Italiano di Ricerche Fenomenologiche - Roma - em parceria com a Pontificia Università Lateranense - Roma Itália, tendo como professores supervisores Angela Ales Belo e Lubomir Zak.

** Pós-Doutorado e Doutorado em Teologia. Professora do Programa de Pós-Graduação em Teologia (Mestrado e Doutorado) PUCPR. E-mail: <cpkperetti@gmail.com>.
} 


\section{INTRODUÇÃO}

$\mathrm{O}$ encontro da teologia com a fenomenologia no século XX representa o diálogo entre grandes pensadores que souberam refletir sobre a realidade em termos fenomenológicos sem, contudo, excluir de suas investigações a perspectiva teológica. A reflexão filosófico-religiosa tem empenhado muitas disciplinas acerca do estatuto científico e epistemológico das atuais Ciências da Religião. Mas, o problema epistemológico emerge com toda sua complexidade no início do século XX como consequência da crise do positivismo e do evolucionismo científico. Surge, de tal modo, no âmbito das ciências humanas, uma variedade de conhecimentos e de métodos aplicados ao estudo das religiões e do sentido da experiência religiosa.

Compreende-se que a religião, por sua natureza inacessível à investigação empírica, é uma manifestação antropológica e histórica, que pode e deve, como qualquer outro fenômeno humano, ser submetida aos métodos de investigação crítica. E, ainda, a religião, como qualquer objeto de investigação empírica, possui uma estrutura própria, que necessita de uma interpretação. $\mathrm{O}$ dado religioso, nessa perspectiva, possui uma verdade que pode ser progressivamente desvelada e reconduzida aos dados elementares subjacentes ${ }^{1}$. É evidente que se pode dizer muitas coisas sobre a natureza da religião e que a multiplicidade de opiniões é muito mais compreensível num contexto multicultural e multirreligioso como o atual, dominado por uma grande fragmentação de perspectivas teóricas. Na introdução ao conceito de religião, no dicionário de Teologia Fundamental, o autor explicita que:

O termo Religião evoca na mente diversas ideias por diferentes pessoas. Alguns o consideram como fé em Deus ou ato de rezar ou de participar a um ritual. Outros compreende-o como ato de meditação sobre alguma coisa de divino; outros, ainda, pensam que está vinculado com uma atitude emocional e individual e que vai além deste mundo; existem também alguns que simplesmente identificam a religião com a moralidade ${ }^{2}$.

Concordamos que, na sua essência, essas definições coincidem com aquelas que encontramos no decorrer da nossa tradição filosófico-religiosa. Entretanto, sustentamos que as diversas concepções de religião são diferentes entre si à medida que uma exclui a outra, ou seja, se considerarmos só o ato de rezar ou só a emoção, só a moralidade, só a meditação pessoal, entre outras concepções. Com base na tradicional etimologia de religião, é possível delinear um núcleo acerca da noção de religião, compreensível a partir dos aspectos anteriormente descritos, como: relação com Deus (religare), em que Deus representa o que já está precedentemente vinculado, visto que dele dependemos totalmente e, por isso, Ele é honrado (relegere). Ademais, como a escolha de honrá-lo cabe ao ser humano, este deveria escolher de fazê-lo (religere e re-eligere).

Com efeito, poderíamos mencionar muitas outras definições de religião, mas nosso objetivo consiste em examinar como, recentemente, a fenomenologia se abriu à teologia e individuar, na fenomenologia de Husserl e de Edith Stein, os pressupostos metodológicos para uma análise fenomenológica da experiência religiosa e mística e também o seu sentido. No referimento aos pressupostos metodológicos para o estudo do fenômeno religioso, seguiremos as linhas traçadas por Angela Ales Bello, filósofa

${ }^{1}$ FILORAMO, G., PRANDI, C. Le scienze delle religioni, p. 15.

2 DHAVAMONY, M. Religione: definizione, p. 919. 
italiana, organizadora e autora de numerosos ensaios e também intérprete do pensamento de Edmund Husserl e Edith Stein ${ }^{3}$.

\section{REPENSAR O SAGRADO NA PERSPECTIVA FILOSÓFICO-FENOMENOLÓGICA}

Ales Bello compreende que a filosofia fenomenológica pode contribuir para um repensar e aprofundar as estruturas internas do sagrado, bem como para especificar melhor a tarefa da Fenomenologia da Religião, através de uma aplicação mais explícita do método fenomenológico proposto por Edmund Husserl e Edith Stein. A propósito disso, a autora assim discorre:

Neste caminho de pesquisa necessitamos de uma base teórica. Nos ajuda a indicar uma direção válida uma impostação aberta de investigação antropológica, religiosa, cultural e política, aquela fenomenológica, proposta pelo filósofo alemão Edmund Husserl (1859-1938), sob sua orientação se formou uma das escolas mais amplas e mais fecundas do século XX na Europa. Numerosos discípulos de Husserl marcaram este século e o seu pensamento continua sendo uma guia também para o atual século. Podemos citar Max Scheler, Edith Stein, Martin Heidegger, para lembrar apenas algumas das personalidades mais notas ${ }^{4}$.

É importante ressaltar que a filosofia fenomenológica contribui e possui uma grande tarefa diante da análise dos "fenômenos", "de todos os fenômenos inclusive os fenômenos histórico-culturais" ". Surge, assim, no âmbito da fenomenologia, a Fenomenologia da Religião, considerada como uma disciplina que "discute o sentido da experiência religiosa em conexão com a antropologia, abrindo-a, para a história das religiões e para a análise de todas as expressões religiosas" ". Examinando a contribuição de van der Leeuw e de Edith Stein, Ales Bello observa que a referência aos dois pensadores pode ser útil para compreender a experiência religiosa tanto no seu sentido positivo quanto negativo, de recusa. Na opinião dela,

as duas posições consentem uma integração sob dois pontos de vista: o primeiro se fundamenta numa descrição essencial em sentido filosófico, fruto de uma escavação na interioridade humana, o segundo é o resultado de uma análise histórica relativa as manifestações que se definem religiosas porque 'mostram' nos rituais, nas invocações, nas elaborações doutrinárias a referência em alguma coisa que transcende os seres humanos. Essas mostram também que o fenômeno religioso não é somente um fenômeno individual, mas envolve em sentido intersubjetivo uma comunidade mais ou menos ampla ${ }^{7}$.

Os dois itinerários de aceitação ou de recusa da presença do divino descritos por Ales Bello remetem à contribuição de Gerardus Van der Leeuw, na sua Fenomenologia da Religião, em que o autor propõe uma investigação histórica do fenômeno religioso. Por meio da história das religiões, Leeuw busca estabelecer o que é a religião para individuar os fenômenos que nomeia como religiosos e não políticos ou artísticos. De acordo com Ales Bello, é sobre este pressuposto de investigação histórica das

\footnotetext{
${ }^{3}$ ALES BELLO, A. Il senso del Sacro, 2012, p. 14-15.

${ }^{4}$ ALES BELLO, A. MOBEEN, S. Lineamenti di antropologia filosofica, p. 11.

${ }^{5}$ ALES BELLO, A. MOBEEN, S. Lineamenti di antropologia filosofica, p. 12.

${ }^{6}$ ALES BELLO, A. MOBEEN, S. Lineamenti di antropologia filosofica, p. 12.

7 ALES BELLO, A. Che cosa è l'esperienza religiosa?, p. 18.
} 
religiões que Leeuw elabora uma Fenomenologia da Religião. Segundo a autora, "isso acontece porque ele percebe em cada manifestação que se declara ou se apresenta como religiosa a presença de uma Potência". No fato religioso, unidade e multiplicidade estão co-presentes e não são contraditórias. Para Ales Bello "esta é uma prova da descrição filosófica da experiência religiosa" que é possível graças ao aprofundamento feito pela antropologia filosófica ${ }^{8}$. Adicionalmente, a filósofa italiana afirma que:

A reflexão sobre a experiência religiosa remete à escavação antropológica, à análise das manifestações históricas a partir de uma circularidade incessante, investigando tanto num caso como no outro, um elemento característico, essencial, invariável na sua qualidade, que pode ser expresso, declinado em vários modos, mas que permanece como busca incessante da Potência e tentativa, não concluída, de atribuir a essa uma configuração9

A essa descrição histórico-filosófica do fenômeno "experiência religiosa", Ales Bello atribui o nome de "Fenomenologia da Religião", pois dá sentido à atualidade e à constatação da presença de uma experiência peculiar, que seguidamente somos tentados reduzir a outra coisa, mas que reemerge sempre e novamente com uma característica específica. Com efeito, consideramos ser esta uma grande contribuição na virada atual da Fenomenologia da Religião, uma fenomenologia que se abre à teologia - que tem por base a revelação natural e sobrenatural. Para Edith Stein, existe "uma esfera do ente que é inacessível à experiência e à razão natural, mas que se faz visível a nós através da Revelação e que impõe novas tarefas ao espírito que a acolhe"10.

A Revelação, como livre autocomunicação do Deus-trinitário à criatura, se apresenta como uma modalidade extraordinária, inacessível de uma Presença \Ausência do divino. Não há dúvidas, que essa modalidade está para ser percebida e conhecida e deve entrar no âmbito da experiência humana. Nesse sentido, a Revelação constitui o objeto formal para nosso estudo e as religiões representam o objeto material. Nas religiões é necessário discernir a presença e a incidência da própria Revelação, sem, contudo, esquecer a mediação das culturas que define a abordagem histórico humana e a busca da experiência de Deus provocadas pela Revelação e que se expressa na objetivação dinâmica da experiência religiosa comunitária ${ }^{11}$.

A perspectiva fenomenológica contribui também para a impostação metodológica das Ciências da Religião em relação à questão do pluralismo das religiões e a práxis do diálogo entre elas ${ }^{12}$. A fenomenologia também contribui para "um diálogo entre teologia e filosofia no mapa global da epistemologia teológica" em que o evento da Revelação é considerado o momento fundativo e a forma originária da teologia cristã. Dessa forma, estamos diante de uma perspectiva chamada a testemunhar no contexto do "pensamento complexo" o proprium originário do teologizar, um proprium que não deve ser reduzido ao conjunto dos traços característicos (do ponto de vista temático e epistemológico) aos modelos históricos mais representativos da teologia, mas que segundo a convicção de muitos teólogos contemporâneos, sensíveis a este tema - deve ser buscado no evento e na fidelidade da revelação e sua própria identidade confessional ${ }^{13}$.

\footnotetext{
${ }^{8}$ ALES BELLO, A. Che cosa è l'esperienza religiosa?, p. 19.

${ }^{9}$ ALES BELLO, A. Che cosa è l'esperienza religiosa?, p. 19.

${ }^{10}$ STEIN, Edith. Ser Finito e Ser Eterno, p. 59.

${ }^{11}$ CODA, P. Il Logos e il nulla, p. 125.

${ }^{12}$ CODA, P. Il Logos e il nulla, p. 51.

${ }^{13}$ ZAK, L. Teologia e epistemologia, p. 74-75.
} 


\section{A FENOMENOLOGIA DA RELIGIÃO}

O termo Fenomenologia da Religião tem sua origem com o holandês P.D. Chantepie de la Saussaye professor de História das Religiões na Universidade de Amsterdam a partir de 1878. Chantepie introduz o termo na primeira edição do seu Manual de História das Religiões para indicar o momento sistemático da disciplina. "Já que o "pressuposto da ciência da religião é a unidade da religião' na multiplicidade de suas formas, têmse que a história das religiões além de investigar as religiões no seu devir, deveria se propor a tarefa de identificar também os aspectos permanentes das religiões"14. Com o termo "fenomenologia", esse autor não indicava um novo método, mas a retomada do método comparativo de orientação positivista evolucionista, preocupado com uma elaboração sistemática do desenvolvimento religioso da humanidade, mas desvinculado das perspectivas teológicas e filosóficas.

A Fenomenologia da Religião surge num contexto de reação ao positivismo. A grande virada fenomenológica, dá-se cinquenta anos mais tarde, com Gerardus van der Leeuw, que encontra sua expressão mais completa na fenomenologia de Edmund Husserl, com o seu método de "ir às coisas próprias", que, com seu esforço antimetafisico e realístico de investigar a realidade que nos circunda, colhe, mediante a suspensão do juízo (epoché) e a capacidade intuitiva do pesquisador, sua essência (visão eidética) e também atribuía fundamento e coerência filosófica às difusas exigências de retornar a estudar a riqueza e a variedade da experiência humana, segundo métodos não redutivos, mas aptos para restituir sua vivente complexidade e variedade.

Segundo Filoramo e Prandi, Gerardus van der Leeuw, em sua obra A Phänomenologie der Religion (1933), afirma que a Fenomenologia da Religião "se apresenta como uma fenomenologia da arte e uma teologia do sacramento ou do trabalho sobre a religião primitiva, essa constitui o terreno entorno do qual gira a inteira produção do pensador holandês"15. A impostação histórico-teorética de Leeuw representa uma importante contribuição para a compreensão das expressões culturais dos povos, em particular, dos povos que manifestam um forte vínculo com as culturas primitivas. As análises do fenomenólogo holandês permitem "mostrar" qual é a essência do fenômeno sacro-religioso e evidenciam que a experiência da essência dos fenômenos é uma experiência humana e se apresenta como um espaço para identificar suas estruturas fundamentais ${ }^{16}$.

Entre o final do século XIX e início do século XX, em reação ao mecanicismo positivista, surgiram novos paradigmas interpretativos, ao redor dos quais se buscava um novo modelo de fenomenologia e de hermenêutica voltada a reivindicar a autonomia do indivíduo e de suas produções espirituais. Filoramo e Prandi destacam as filosofias vitalistas com Bergson e Georg Simmel. Segundo os autores: "a realidade aparecia agora dominada pelas leis vitais e não mais mecanicistas; em particular, a realidade humana se manifestava nos seus aspectos mais vitais e irracionais". No horizonte de uma nova base epistemológica de tipo organicístico, destacam-se pensadores como Wilhem Dilthey que buscava afirmar a autonomia das ciências do espirito ${ }^{17}$. Essa nova forma de se colocar diante da natureza do homem resultava, do ponto de vista metodológico, uma atitude reducionista. A mudança hermenêutica realizada, a partir de Schleiermacher, de Dilthey, contribui para a construção de uma fenomenologia não mais simplesmente

\footnotetext{
${ }^{14}$ FILORAMO, G., PRANDI, C. Le scienze delle religioni, p. 31-33.

${ }^{15}$ FILORAMO, G., PRANDI, C. Le scienze delle religioni, p. 35

${ }^{16}$ ALES BELLO, A. Il senso del Sacro, p. 22.

${ }^{17}$ FILORAMO, G., PRANDI, C. Le scienze delle religioni, p. 34-35.
} 
descritiva, mas hermeneuticamente orientada. Como já afirmamos, Leew se destaca com a sua Fenomenologia da Religião ${ }^{18}$.

Nicola Reali, no Dicionário Crítico de Teologia organizado por Piero Coda ${ }^{19}$, enfatiza as principais linhas de desenvolvimento da fenomenologia e sua relação com a teologia. Os fenomenólogos que mais contribuíram, nas últimas décadas, para este procedimento são M. Henry (1922-2002) e J.-L.Marion (1946). Para ambos, a filosofia, depois que conheceu as investigações husserlianas do primado da intuição doada sobre a intenção, não pode simplesmente abrir os arquivos de suas bibliotecas e oferecer ao filósofo contemporâneo um instrumento categorial e um "renovado" método, como se nada tivesse acontecido no campo da relação entre filosofia e teologia, nem o filósofo pode esquecer-se de ter a vocação do dizer teológico ainda antes que Husserl. Certamente, Henry e Marion não são os filósofos pioneiros neste campo. Com Descartes em diante, a filosofia sempre se ocupou dos fenômenos revelados para se perguntar sobre qual "realidade" se deve reconhecer, e, consequentemente, qual leitura deve fazer o sujeito que se coloca diante do fenômeno. O significado da participação de Marion e Henry, nesta tradição, consiste realmente no exercício de esclarecimento e de aprofundamento da leitura do fenômeno, do que se deve colocar em evidência dos fenômenos revelados que fazem parte da realidade e sobre o tipo de transcendência que é necessário admitir para a descrição dos fenômenos que se dão no campo da fenomenalidade em que o sujeito humano concretamente vive.

\section{A VIRADA ATUAL NA FENOMENOLOGIA DA RELIGIÃO}

De acordo com Ales Bello, a Fenomenologia da Religião de Leeuw, sem dúvidas, trouxe grandes contribuições para a descrição histórico-filosófica do fenômeno da experiência religiosa nas culturais primitivas, sublinhando a presença do sagrado nas religiões históricas. Mas a autora ressalta que "a íntima estrutura do fenômeno do sagrado" não chegou, ainda, a ser investigada. Diante desta lacuna, a filósofa vê a necessidade de repropor a questão sobre o método mais adequado para a análise da estrutura interna do fenômeno e sugere adotar a fenomenologia filosófica proposta por Husserl, porque "as indicações advindas do método husserliano, se revelam como instrumentos úteis para entrar nos meandros das dimensões sacro-religiosas" ${ }^{20}$. Ales Bello delineia, nas primeiras páginas do livro Il senso del sacro. Dall'arcaicità alla desacralizzazione, um caminho de análise do fenômeno religioso. A seguir, elencamos alguns pontos fundamentais da obra.

Num primeiro momento, Ales Bello observa que a dimensão sacro-religiosa pode ser analisada não apenas do ponto de vista teorético. Diante disso, ela se pergunta sobre o sentido da experiência sacro-religiosa, mas constata que é necessário olhar também para suas concretizações históricas, para delinear, desta forma, as características do sacro-primitivo, as articulações e as modalidades que as expressões religiosas sucessivas assumem nas suas diversas configurações no contexto da cultura ocidental e de outros contextos culturais. Para a autora, não se trata uma reconstrução histórica sistemática, mas de realizar incursões e investigações no vasto território das manifestações sacroreligiosas, nas suas diferenças e contraposições, e também nos seus vínculos e nos seus entrelaçamentos, para colher suas características fundamentais e o lugar que ocupam

${ }^{18}$ FILORAMO, G., PRANDI, C. Le scienze delle religioni, p. 34-35.

${ }^{19}$ REALI, N. Fenomenologia e Teologia, p. 559-562.

${ }^{20}$ ALES BELLO, A. Il senso del Sacro, p. 13-14. 
na complexa estrutura humana e social ${ }^{21}$. O caminho proposto sinaliza, de tal modo, uma virada, no âmbito da Fenomenologia da Religião, a partir da fenomenologia de Husserl. A compreensão do "sentido do sagrado", no âmbito da experiência religiosa como construtiva de todos os seres humanos, passa em primeiro lugar pela análise antropológica em sentido filosófico, conduzida pela impostação fenomenológica que coloca em evidência a complexidade e o sentido da dimensão religiosa e, em segundo lugar, a análise verte sobre o fenômeno religioso nas suas especificidades e modalidades de manifestação do divino.

Ales Bello, no seu livro Il senso del Sacro, sugere a abordagem histórica como um dos caminhos de aproximação ao fenômeno religioso. Para compreender o sentido da experiência religiosa, segundo a estudiosa, é necessário distinguir a relação entre sagrado e religioso, ou seja, "as diferenças entre diversas experiências ou comportamentos os quais, embora tenham alguns elementos comuns, se diversificam pelo modo de entender o divino, usando tal expressão somente em sentido genérico"22.

Ainda, de acordo com a autora, a História das Religiões ${ }^{23}$ apresenta-nos um panorama com sentido diacrônico e sincrônico das experiências religiosas que nem sempre é possível se adentrar na sua interioridade. "Sagrado" e "Profano", muitas vezes, são contrapostos, e se poderia considerar que as últimas redescobertas do sagrado foram usadas de maneira polêmica em relação às religiões positivas. Por isso, é necessário refletir sobre a relação entre sagrado e profano. Mas qual é o sentido de repercorrer o caminho histórico das religiões?

Entende-se que o sentido de repercorrer o caminho histórico e retornar às expressões primitivas do sagrado consiste em compreender as estruturas das religiões mais próximas a nós em correlação com o fenômeno do sagrado e as razões de seu retorno no contexto de uma sociedade secularizada marcada por uma crescente dessacralização. A história das religiões desempenha um papel importante na compreensão da experiência religiosa; contudo, essa se depara com questões teóricas específicas de orientação sobre o próprio objeto de pesquisa, que obriga o estudioso a alargar os horizontes de sua pesquisa para áreas de conhecimento afins como a filosofia, a antropologia cultural consideradas "interlocutoras principais" para uma compreensão teórica e prática do fenômeno religioso ${ }^{24}$. As expressões primitivas se constituíram objeto de investigação da antropologia cultural, entretanto, o risco que os antropólogos culturais correm é, muitas vezes, limitar-se à descrição dos fenômenos relevantes, colocando em evidência apenas o aspecto social. A partir dessas constatações, compreende-se que o sagrado se revela como um campo sustentado por diferentes abordagens, apesar disso, insuficientes para compreender o seu sentido. Surge, então, alguns questionamentos: qual perspectiva assumir para a investigação do sagrado? Como definir o fato religioso e distingui-lo de um acontecimento político, de um fenômeno artístico? É necessário aferrar o sentido dos fenômenos, proceder a partir de critérios que possuem uma sua essencialidade. E qual perspectiva metodológica seguir? Como se orientar nesta busca? Nas páginas introdutórias do texto Lineamenti di antropologia filosofica de Angela Ales Bello, encontramos indicações metodológicas de aplicação do método fenomenológico de Husserl ao estudo da religião. A autora assevera que:

\footnotetext{
${ }^{21}$ ALES BELLO, A. Il senso del Sacro, p. 14.

${ }^{22}$ ALES BELLO, A. Il senso del Sacro, p. 12.

${ }^{23}$ ALES BELLO, A. Il senso del Sacro, p. 12.

${ }^{24}$ ALES BELLO, A. Il senso del Sacro, p. 13 e 18.
} 
Uma vez compreendido do ponto de vista essencial o significado de um fenômeno, é possível também passar ao nível valorativo, isto é, se perguntar se é portador de valores, que foram individuados da análise antropológica, base para uma tomada de posição ${ }^{25}$.

Trata-se de compreender a circularidade entre teoria e práxis, pois para aprofundar o sentido das religiões é necessária uma descrição histórica orientada por um critério de orientação crítica relacionada, sobretudo, ao sentido da própria experiência religiosa ${ }^{26}$. A autora exemplifica dizendo que, para aprofundar o sentido do islamismo e no seu contexto o fenômeno do sufismo, é necessária uma descrição histórica do islamismo. A leitura do fenômeno consiste em examinar a datidade histórica dos fenômenos para verificar sua origem no interior de uma religião, isto é, sua especificidade. De certa maneira, significa considerar que cada fenômeno cultural é expressão espiritual dos seres humanos, é um produto individual antes de ser um produto coletivo ${ }^{27}$.

Em síntese, três são os aspectos evidenciados: a tomada de consciência da condição histórica, que implica positivamente o contínuo empenho na assunção e expressão nova do significado originário e contemporaneamente hermenêutico; a compreensão do valor positivo das experiências religiosas "Outras", enquanto experiências que brotam do centro da existência humana aberta e visitada pelo Mistério; o reenvio a qualidade original da experiência, seja no seu evento fundativo, seja naquilo que a torna atual e presente em cada tempo e que por si só coloca o ser humano numa singular relação interna ou externa com o fato religioso.

\section{A CONTRIBUIÇÃO METODOLÓGICA DE ANGELA ALES BELLO NO ESTUDO DO FENÔMENO RELIGIOSO}

Repercorrendo os vários escritos de Ales Bello no âmbito da fenomenologia, encontramos em sua produção um fio condutor entre fenomenologia e religião. Embora se movimente em diversas perspectivas, em cada sua obra está presente uma ânsia metafisica e uma exigência fundativa necessária para a pesquisa fenomenológica, de confrontar-se com a questão filosófica do problema de Deus.

A esse propósito vale destacar, além das numerosas contribuições já citadas no corpo deste trabalho, os estudos de interesse pelas obras de Husserl e Stein dos anos 1970 em relação à questão do Logos, do cristianismo e do tomismo. São eles: A proposito della "philosophia perennis". Tommaso d'Aquino e E. Husserl nell'interpretazione di E. Stein ${ }^{28}$; Edith Stein: da E. Husserl a Tommaso d'Aquino, Tomismo e Antitomismo ${ }^{29}$; Fenomenologia e tomismo in E. Stein. Tommaso d'Aquino nella storia del pensiero ${ }^{30}$.

$\mathrm{Na}$ vasta produção de Ales Bello, além do interesse pela fenomenologia e do tomismo, pela dimensão histórica da questão do Logos, emerge também, nos anos 1980, o interesse pelo exame da questão metafisica e o problema de Deus na fenomenologia husserliana e pela relação entre filosofia e ciências, sintetizado na sua obra Husserl. Sul problema di Dio ${ }^{31}$. É um texto fundamental para compreender o interesse da autora pela problemática teológico-religiosa e pelo desenvolvimento de uma arqueologia do

\footnotetext{
${ }^{25}$ ALES BELLO, A. MOBEEN, S. Lineamenti di antropologia filosofica, p. 12.

${ }^{26}$ ALES BELLO, A. MOBEEN, S. Lineamenti di antropologia filosofica, p. 12.

${ }^{27}$ ALES BELLO, A., MOBEEN, S. Lineamenti di antropologia filosofica, p. 13.

${ }^{28}$ ALES BELLO, A. A proposito della "philosophia perennis, p. 441-451.

${ }^{29}$ ALES BELLO, A. Edith Stein, p. 265-276.

${ }^{30}$ ALES BELLO, A. Fenomenologia e tomismo in E. Stein, p. 469-479.

${ }^{31}$ ALES BELLO, A. Husserl, p. 131.
} 
saber religioso, que deve ser entendida como uma escavação mais profunda para uma possível compreensão das formações culturais e das tradições. Destaca-se, ainda, nesse período, os estudos sobre a contribuição de Husserl na análise e no confronto com outras culturas tanto do ponto de vista histórico das religiões quanto religioso, no âmbito dos quais emerge também a problemática entre filosofia e religião ${ }^{32}$. De acordo com Ales Bello, mediante uma arqueologia fenomenológica (uma investigação histórica e filosófica), é possível compreender a formação originária do pensamento religioso. Dessa forma, a "arqueologia do saber religioso tem por missão controlar a incidência dos dois momentos no desenvolvimento de crenças religiosas e, mais geralmente na discussão do problema de Deus"33. Ao lado da proposta de uma arqueologia do saber religioso, como proposta teorética que oferece a fenomenologia um percurso factível em seio a uma eventual metafísica fenomenológica, coloca-se, nos anos 1990, a questão hyletica ${ }^{34}$.

O problema da hylética insere-se no horizonte fundativo e pré-categorial do pensamento religioso de Husserl e torna-se uma questão central na filosofia de Ales Bello $^{35}$. A autora recorre seguidamente ao exemplo do bloco de granito ${ }^{36}$ utilizado por Edith Stein na obra La Struttura della persona umana, para explicar o sentido da hylética como o momento da formação da matéria, na qual se revela um sentido. Segundo ela, "essa é cheia de sentido, porque tal formação é constituída por um princípio estrutural próprio" 37 . A formação da matéria possui uma estrutura precisa, rica de sentido, que chama nossa atenção de maneira particular.

De acordo com Ales Bello ${ }^{38}$, no primeiro volume das Ideias, Husserl delineia seu método de pesquisa que consiste em duas passagens: redução eidética - a mais evidente possibilidade por parte do ser humano de colher a essência das coisas (Sache) -; a aplicação do conhecimento essencial no âmbito da subjetividade. A autora inicia um trabalho de escavação que Husserl compara com aquela do arqueólogo e que tem como momento fundamental a evidenciação dos atos que são vivenciados pelo ser humano (Erlebnisse), dos quais se tem consciência. Descreve, assim, a esfera da pura consciência como resíduo fenomenológico, que constitui o novo campo da pesquisa, sobre o qual é possível colher, na sua pura essência, as vivências da percepção, da lembrança e da imaginação, as quais se apresentam em conexão concreta como o fluir da corrente de consciência e remetem intencionalmente, enquanto momentos noéticos, àquilo que é percebido, lembrado e imaginado, como conteúdo da consciência, que constituem o aspecto noemático, mas ulteriormente podem referir-se àquilo que transcende à própria consciência. Um exemplo disso é o objeto real enquanto percebido.

Tudo isso diz respeito tanto ao conhecimento do mundo físico quanto àquele do mundo interior que pode reflexivamente ser colocado em evidência. Mas a análise não pode se contentar de permanecer na imanência, mas se abrem, assim, vias que ultrapassam a consciência e conduzem à transcendência. Partindo da análise das correntes de consciência, somos obrigados a admitir a transcendência não só do mundo, mas, também, de Deus. Para Ales Bello, "trata-se, de colocar em evidência a existência de um absoluto anunciado na consciência, mas totalmente diferente da própria consciência e aquela do mundo"39.

\footnotetext{
${ }^{32}$ ALES BELLO, A. Husserl, p. 132-137.

${ }^{33}$ ALES BELLO, A. Husserl, p. 143.

${ }^{34}$ GHIGI, N. La hyletica nella fenomenologia, p. 405-425.

${ }^{35}$ ALES BELLO, A. Culture e religioni, p. 86.

${ }^{36}$ STEIN. E. La Struttura della persona umana, p. 166-167.

${ }^{37}$ ALES BELLO, A. MOBEEN, S. Lineamenti di antropologia filosofica, p. 69.

${ }^{38}$ ALES BELLO, A. L'universo nella coscienza, p. 165.

${ }^{39}$ ALES BELLO, A. L'universo nella coscienza, p. 166, nota 92.
} 
Partindo da análise da corrente de consciência e das vivências, segundo Ales Bello, Husserl admite que há uma espécie de imanência de Deus na consciência e essa experiência remete sempre a um fluxo do vivido na subjetividade. A transcendência de Deus não se dá diretamente unida à consciência reduzida. Nesta caracterização, não se diz absoluto para nenhuma realidade do mundo, pois ela não pode constituir-se em ponto de partida para um caminho de fundamentação absoluta. A experiência do mundo não pode ser dita absoluta (in se), pois se situa na dimensão do contingente. Mas há um tipo de experiência que se constitui como algo absoluto, como "verdadeiro princípio de todos os princípios", como princípio absoluto. Trata-se da autoexperiência reflexiva do "eu sou". Há, portanto, um outro modo de anunciar a transcendência divina e as 'notícias intuitivas', que, com base no pensamento teorético, é possível tornar inelegível a potência unitária do suposto princípio teológico ${ }^{40}$. Ainda que Husserl admita a possibilidade de um princípio teológico, ele afirma que "o nosso olhar imediato não vai a teologia, mas a fenomenologia, por mais que esta possa ter indiretamente uma grande importância para aquela". Husserl retoma em vários lugares o tema teológico (imanência de Deus na consciência) e busca fornecer soluções, mas o que nos interessa das suas afirmações é que o divino está presente em todas as consciências e em todas as almas e se revela como essencialmente pessoal. Tudo isso, diz Ales Bello, induziu James Hart, um dos poucos estudiosos desse aspecto das análises husserlianas sobre a mística, a encontrar uma convergência com a tradição platônicaagostiniana e muito mais com o misticismo ocidental. O que nos interessa nessa sede não são as conexões com a mística, mas sim que Husserl admite a presença de Deus na alma, compreendida como pessoa, que estabelece com a criatura uma relação de amor e que lhe indica o fim ao qual se deve orientar. Isso sim, Husserl sustenta com insistência.

É a partir da perspectiva husserliana e steiniana que Ales Bello faz emergir do momento hylético como espaço de sentido, como esfera de onde emergem os pressupostos de doação de sentido. A intencionalidade que caracteriza a hylética torna-se o pressuposto para poder redescobrir, na matéria, os sinais de uma transcendência que transcende todas as coisas. A constituição das coisas, por uma realidade espiritual, permite poder aproximar o sentir da alma ao sentir do espirito, até a mística. É aqui que se dá provavelmente o encontro entre fenomenologia e mística, que "se apresenta como eficaz para um aprofundamento reciproco" "41. Se a fenomenologia nos permite perceber os sinais do Absoluto, que se manifestam na vida espiritual da pessoa humana, a mística, é, por sua vez, aquela modalidade que nos possibilita acessar, sem limites, a esta dimensão.

Disso podemos inferir que a investigação teórica de uma experiência religiosa movimenta-se a partir do fato e de sua descrição para buscar o seu significado. Ales Bello, seguindo os passos da fenomenologia husserliana e steiniana, propõe, como ponto inicial para o estudo das religiões, uma análise antropológica. Já que partimos de um fato humano, é necessário perguntar quem é o ser humano, como é que é possível conhecê-lo em sua estrutura própria e qual o sentido dos atos que realiza e de suas produções culturais ${ }^{42}$. Dentre estas estão as manifestações religiosas, que não se colocam simplesmente uma ao lado da outra, mas constituem o húmus profundo da natureza humana ${ }^{43}$. O método é o da escavação arqueológica proposto pela fenomenologia de

\footnotetext{
${ }^{40}$ ALES BELLO, A. L'universo nella coscienza, p. 166, nota, 93.

${ }^{41}$ ALES BELLO, A. L'universo nella coscienza, p. 173.

${ }^{42}$ ALES BELlO, A. MOBEEN, S. Lineamenti di antropologia filosofica, p. 17; ALES BELLO, A. Il senso del Sacro, p. 29.

${ }^{43}$ ALES BELLO, A. MOBEEN, S. Lineamenti di antropologia filosofica, p. 17.
} 
Husserl, que investiga os fatos humanos que se manifestam, ou seja, os fenômenos para buscar seu sentido. É possível olhar para o ser humano, abstraindo-o do contexto no qual vive, isolando-o provisoriamente para investigar suas estruturas, mas o objetivo é proceder com uma análise que opera em um contexto interpessoal, disso é necessário estar conscientes. Este tipo de investigação é fundamental para enfrentar qualquer questão de caráter religioso, político, artístico, científico ${ }^{44}$.

É importante ressaltar que, fazendo uso do método fenomenológico, é possível uma abordagem comparativa das expressões culturais. Mas surge o seguinte questionamento: é possível exprimir juízos de valor a respeito da comparação cultural? Depois da progressiva diminuição da presença e da experiência religiosa na cultura ocidental, em nossos dias, estamos percebendo, de maneira surpreendente, que isso não acontece em outras culturas e que elas não se encontram "numa fase de desenvolvimento" rumo a uma experiência semelhante a experiência cristã.

Pode-se afirmar, então, que a fenomenologia da experiência religiosa exercita uma noemática, que é o correlato da consciência, a intenção, aquilo sobre o qual se reflete. Nesse sentido, a Fenomenologia da Religião se configura como uma disciplina peculiar, como uma elaboração de uma teoria da consciência religiosa, em um sentido "técnico". Este interesse específico está presente no pensamento de Edith Stein, com elaborações originais e profundas. Ela desempenha um papel essencial para a fundação de uma antropologia filosófica sobre a base fenomenológica, que podemos definir como um verdadeiro personalismo. Seu interesse se concentra na esfera da interioridade. O exercício da redução eidética impulsionou o desenvolvimento de uma ciência do fenômeno religioso e místico: na epistemologia analítica das vivências da consciência, trata-se de acolher com afinidade as diferenças: para o "religioso", a acolhida/aceitação do divino, e para o "místico", a perda de centralidade e/ou esvaziamento do eu como universal, via para a interioridade, para a alma e para Deus ${ }^{45}$. O primeiro aspecto enfatiza atividade, o segundo, passividade. Dessa forma, ambos são vivências/experiências vividas sob signo da liberdade. Essas experiências nos remetem ao Deum et animam scire cupio (quero conhecer a Deus e a alma), de santo Agostinho.

A relação entre fenomenologia e religião, brevemente delineada na reconstrução do percurso filosófico Ales Bello, é tema central também da obra: Edith Stein o dell'armonia ${ }^{46}$. Nesta obra, a autora alude à "circularidade entre filosofia e teologia" enfatizada na Fides et Ratio (§ 73) e a eventual junção de filosofia e mística que, como já vimos, caracteriza frequentemente seus escritos e que Edith Stein considera como "duas vias de conhecimento da verdade" 47 .

Uma vez reconstruído o caminho filosófico e religioso de Edith Stein, Ales Bello evidencia que a impostação fenomenológica permanece presente nas suas obras quando "a virada metafisica" investe seus pensamentos e, também, quando ela se distancia de um conceito transcendental de transcendência para voltar àquele metafísico da teologia clássica. Por essas razões, Ales Bello faz referência a uma exigência viva em Edith Stein de "colocar harmonia" entre o particular e o absoluto, compreendida não como "uma mera operação de uma junção", mas, sobretudo, como algo que é possível "porque se fundamenta sobre uma autêntica unidade de tipo ontológico, que está na base da diversidade e da pluralidade" ${ }^{48}$. Contudo, essa unidade não deve ser pensada "de

\footnotetext{
${ }^{44}$ ALES BELLO, A. MOBEEN, S. Lineamenti di antropologia filosofica, p. 17.

${ }^{45}$ MANGANARO, P. Verso l'Altro, p. 195-196.

${ }^{46}$ ALES BELLO, A. Edith Stein o dell'armonia, 2009, p. 110.

${ }^{47}$ ALES BELLO, A. Edith Stein o dell'armonia, p. 113-114.

${ }^{48}$ ALES BELLO, A. Edith Stein o dell'armonia, p. 224.
} 
modo que possa excluir ou absorver a diversidade, mas no sentido que as compreende, levando-as, contudo, a viver na sua autonomia"49.

As questões filosófica e religiosa se apresentam como dois caminhos diferentes, mas complementares, na busca da verdade. Cada um desses caminhos possui um percurso, uma importância gnosiológica e uma dignidade própria. Contudo, há no seu interior, uma unidade que, embora mantendo-se diferente, é representada pela própria Verdade. O sentido de "colocar harmonia" significa, então, neste aspecto, falar de uma "harmonia como unidade, unidade de diferenças", mas ao mesmo tempo como "harmonia das diferenças não obstante as diferenças" ${ }^{50}$. Harmonia na busca da verdade significa reconhecer a diferença de um sentido no seio do próprio horizonte, sem querer omitir uma das duas partes opostas, mas mantendo a unicidade de intenções, no diferente percurso, ou seja, na complementariedade, conforme lembra Agostinho de um único objetivo: o conseguimento da verdade.

Nesta busca, segundo Ales Bello, somos levados a procurar "o sentido profundo de todas as coisas". Mas este "caminho regressivo", continua a autora, "é o caminho que Edith Stein indica como caminho em busca da verdade, no qual podemos encontrar interrupções e desvios, porque paramos para trocar as verdades particulares com a Verdade. E a Verdade é harmonia [...], esperança, [...] luz que dá sentido a tudo, também àquilo que aparentemente é contraditório, contrastante, diferente, múltiplo e que nessa encontra sua razão e sua unidade" ${ }^{51}$.

\section{CONCLUSÃO}

O apelo de Stein de "colocar harmonia" deve ser entendido, segundo Ales Bello, "não no sentido puramente extrínseco de um possível acordo convencional, mas no sentido de um encontro sobre um terreno de verdades". Por isso, deve ser compreendido como carregado de "um valor teórico que supera também as suas posições e pode nos guiar em nosso caminho não somente intelectual, mas também moral e religioso" "52. Este é o sentido profundo de todas as coisas e, é também o caminho que se desvela diante de nós para entender a relação intima entre intersubjetividade e Trindade. O conceito de Revelação Trinitária além de se apresentar como um tema central do debate teológico contemporâneo resulta decisivo também no confronto entre filosofia e teologia, muito bem descrito por Edith Stein na sua obra magna Ser finito e Ser Eterno.

É, portanto, a necessidade de um alicerce sobre o qual construir a existência pessoal e social que move Edith Stein, discípula de Edmund Husserl, a percorrer os caminhos da investigação filosófica e a instaurar uma justa relação entre filosofia e teologia. A prova da fecundidade de tal relação é oferecida por Ales Bello em seus escritos que, além de apresentar o pensamento de Edith Stein como algo vivo, introduz, também, o leitor na compreensão do seu itinerário existencial, filosófico e espiritual. As páginas escritas deixam transparecer o encontro de Angela Ales Bello com a fenomenologia de Husserl e de Edith Stein, seu "encantamento" pela busca humana da verdade e pelo seu filosofar estritamente entrelaçado com a vida.

\footnotetext{
${ }^{49}$ ALES BELLO, A. Edith Stein o dell'armonia, p. 236.

${ }^{50}$ ALES BELLO, A. Edith Stein o dell'armonia, p. 236.

${ }^{51}$ ALES BELLO, A. Edith Stein o dell'armonia, p. 239.

${ }^{52}$ ALES BELLO, A. Edith Stein o dell'armonia, p. 242.
} 


\section{REFERÊNCIAS}

ALES BELLO, Angela. A proposito della "philosophia perennis". Tommaso d'Aquino e E. Husserl nell’interpretazione di E. Stein. In: Sapienza, 27, Napoli 1974. p. 441-451.

Che cosa è l'esperienza religiosa? Un'analise fenomenologica. In: ALES BELLO, Angela; GRASSI, Onorato. Pensare l'esperienza religiosa. Milano: Mimesis, 2010.

Culture e religioni. Una lettura fenomenologica. Roma, Città Nuova, 1997.

Edith Stein o dell'armonia. Esistenza, pensiero, fede. Roma: Studium, 2009.

Edith Stein: da E. Husserl a Tommaso d'Aquino, Tomismo e Antitomismo, Memorie domenicane 7, Pistoia 1976. p. 265-276.

Fenomenologia e tomismo in E. Stein. Tommaso d'Aquino nella storia del pensiero. In: Atti del Congresso Internazionale: Tommaso d'Aquino nel suo settimo centenario. Napoli: Edizioni Domenicane, 1977. p. 469-479.

. Husserl. Sul problema di Dio. Roma: Studium, 1985.

. Il senso del Sacro. Dall'arcaicita ala desacralizzazione. Roma: Castelvecchi, 2014.

L'universo nella coscienza. Introduzione alla Fenomenologia: Edmund Husserl, Edtih Stein, Hedwig Conrad-Martius. Pisa: Ediioni ETS, 2007.

ALES BELLO, Angela; MOBEEN, Shahid. Lineamenti di antropologia filosofica. Fenomenologia della religione ed esperienza mística islamica. Roma: Editrice APES, 2012.

CODA, Piero. Il Logos e il nulla. Trinità Religione e Mistica. Roma: Città Nuova, 2003.

DHAVAMONY, Mariasusai. Religione: definizione. In: LATOURELLE, René; FISICHELLA, Rino (Ed.). Dizionario di Teologia Fondamentale. Ed. It. a cura di R. Fisichella. Assis: Cittadella, 1990. p. 919 .

FILORAMO, Giovanni, PRANDI, Carlo. Le scienze delle religioni. 3. ed. Brescia: Editrice Morcelliana, 1997.

GHIGI, Nicoletta. La hyletica nella fenomenologia. A proposito di alcuni scritti di Angela Ales Bello. In: MANGANARO, Patrizia., FERRI, Riccardo. Gesto e parola. Ricerche sulla Rivelazione, Roma: Città Nuova, 2005. p. 405-425.

La rinascita della fenomenologia in Italia. Angela Ales e il centro italiano di ricerche fenomenologiche. In: Segni e Comprensione. Università del Salento (Italy), a. XXIV n.s., n. 70, p. 107-124, 2010. https://doi.org/10.1285/i18285368aXXIVn70p107

MANGANARO, Patrizia. Verso l'Altro. L'esperienza mistica tra interiorità e trascendenza. Roma: Città Nuova, 2002.

REALI, Nicola. Fenomenologia e Teologia. In: LACOSTE, Jean-Yves. Dizionario critico di teologia. Edizioni Italiana a cura di Piero Coda. Roma: Borla-Città Nuova, 2005. p. 559-562.

STEIN, Edith. Essere finito e Essere eterno. Per Una elevazione al senso dell'essere. Roma: Città Nuova, 1988.

La struttura della persona umana. Corso di Pedagogia filosofica. Roma: Città Nuova, Edizioni OCD, 2013.

ZAK, Lubomir. Teologia ed epistemologia. Questioni emergenti e prospettive attuali. Per la Filosofia. Filosofia e insegnamento. Anno XXII, n. 64. Maggio-Agosto. Estratto. Instituto Editorial e Poligrafici Internazionali. Pisa. Roma: 2005, p. 74-75.

Recebido em: 14/11/2016

Aprovado em: 16/06/2017

Clélia Peretti

Rua Oyapock, 99, apto. 302 - Cristo Rei

80050-450 - Curitiba - PR - Brasil 